\title{
COMPARTIMENTAÇÃO GEOMORFOMETRICA DA BACIA DO RIO NEVERI, VENEZUELA
}

\author{
María José Entrena Pineda ${ }^{(a)}$, Luis Eduardo de Souza Robaina ${ }^{(b)}$, Romario Trentin ${ }^{(c)}$, Rhael David \\ Lara Partida ${ }^{(\mathrm{d})}$ \\ (a) Departamento de Geociências/ Universidade Federal de Santa Maria, mariajoseentrena@ gmail.com \\ (b) Departamento de Geociências/ Universidade Federal de Santa Maria, rhael.lara5@gmail.com \\ (c) Departamento de Geociências/ Universidade Federal de Santa Maria romario.trentin@gmail.com \\ (d) Departamento de Geociências/Universidade Federal de Santa Maria, lesrobaina@yahoo.com.br
}

\section{Eixo: GEOTECNOLOGIAS E MODELAGEM ESPACIAL EM GEOGRAFIA FISICA}

\begin{abstract}
Resumo
O avanço das geotecnologias e informática aplicadas no campo da geomorfologia é crescente, o uso de técnicas de inferência espacial para identificação de distintas unidades do relevo, apoia a análise digital do relevo. Nesse sentido, o presente trabalho apresenta o experimento que identificou quinze unidades geomorfométricas, apoiando-se em atributos topográficos derivados do MDE da bacia hidrografica do rio Neveri, Venezuela. Os atributos topográficos empregados foram: altitude, declividade, forma da vertente (plano e perfil de curvatura). Baseia-se na proposta de mapeamento automatizado, que consiste no cruzamento dos atributos topograficos utilizando uma árvore de decisões com base nos valores menor e maior que média da altitude, declividades menor que 5\%, 5$15 \%$ e maior que $15 \%$, planos convergentes e divergentes e perfis côncavo e convexo . A area de estudo é composta de relevos abruptos nas partes altas e medio curso da bacia e planas no curso baixo do rio.
\end{abstract}

Palavras chave: bacia hidrográfica, geomorfometria, atributos topográficos, unidades geomorfometricas

\section{Introdução}

A Geomorfologia é um dos principais ramos da geografia física, a sua abordagem permite a compreensão do relevo como um elemento dinâmico da superfície da Terra e são incorporados como um espaço onde os processos sociais são materializados. Seu desenvolvimento no espaço temporário permite a compreensão dos processos de dinâmica da superfície.

Neste sentido Christofoletti (1980) define geomorfologia como a ciência que estuda a origem e evolução do relevo na superfície da Terra. Onde o seu principal objetivo é a caracterização geomorfológica de uma área ou região que representa as formas atuais de superfície particular, e inclui informações sobre a morfometria e morfogênese do terreno (ROSS, 1992).

Segundo Trentin e Robaina (2012), o estudo da geomorfologia permite a análise espaço-temporal dos processos que moldam o relevo da Terra, onde é possível identificar, analisar e, portanto, prever processos 
de degradação ambiental, que estão ligados aos elementos físicos em uma determinada área geográfica. Desta forma, a análise geomorfológica está emergindo como uma importante ferramenta para análise e determinação de ações para mitigação para evitar impactos sobre o meio ambiente.

A caracterização geomorfológica representa as formas de produtos abrangentes e processos naturais e antrópicos, tanto do passado e do presente dos componentes do ambiente físico. Neste sentido, Penteado (1985), destaca que a classificação geomorfológica inclui características morfométricas e morfológicas e os processos morfodinâmicos e morfogenéticos.

De acordo com Wood (1996) a parametrização do relevo refere-se à representação quantitativa das características morfológicas da paisagem, que são continuamente descritas pelas equações aplicadas, a representação numérica e modelos de altimetria onde os atributos geomorfométricos são derivados. Esses atributos representam mensurações quantitativas das formas do relevo por meio de técnicas empregadas nos Sistemas de Informações Geográficas (SIG) (HENGL, 2003; WOOD, 1996).

A importância da compartimentação do relevo reside na utilização de diferentes aplicações no domínio do planeamento e ordenamento do território, zoneamento ambiental, mapeamento geomorfológicos, pedológicos, de susceptibilidade geoambiental, entre outros (TRENTIN; ROBAINA; SILVEIRA, 2015). A compartimentação geomorfométrica é suportada por atributos quantitativos (variáveis) morfométricas do componente topográfico, que representam elementos quantificáveis na superfície da terra. Estes atributos topográficos podem ser parametrizados utilizando variáveis como a altitude, declividade, aspecto, curvaturas (plano, perfil), área de contribuição, entre outros (GUADAGNIN; TRENTIN, 2014). Os elementos acima mencionados de forma simplificada têm a capacidade de descrever a dinâmica da superfície da Terra, apresentarem vestígios do seu passado, do seu presente e como o seu futuro (com base nas condições atuais); e, assim, gerar estudos em vários níveis de detalhe, podendo vir a ser fontes de zoneamentos de diagnóstico e ambientais.

A bacia pode ser considerada como um exemplo de sistema complexo geomorfológico porque tem todas as características inerentes a um tal sistema. Nesse sentido, a bacia é aberta para os fluxos de energia e um sistema, em que as entradas são representadas pela precipitação e a forças e saídas tectônicas subjacente para a perda de água e sedimentos. Sua configuração hierárquica é outra característica básica dos sistemas geomorfológicos complexos (MATTOS; FILHO, 2004).

Independentemente da perspectiva escolhida para o sistema de análise geomorfológico (bacia hidrográfica), a identificação dos subsistemas não pode ser executada individualmente com cada um dos seus componentes: estrutura, função e organização, que são o resultado das inter-relações entre eles (MATTOS; FILHO, 2004). 


\section{OS DESAFIOS DA GEOGRAFIA FÍSICA NA FRONTEIRA DO CONHECIMENTO \\ Instituto de Geociências - Unicamp \\ Campinas - SP \\ 28 de Junho à 02 de Julho de 2017}

Assim, a bacia representa uma unidade de análise para o diagnóstico de várias situações de sistemas ambientais presentes nele, e gerar entradas para o desenvolvimento desta.

Com base nessa discussão o trabalho utiliza uma área de estudo de bacia hidrográfica para fazer uma delimitação com base em recursos naturais e permitir a discussão integral dos elementos que determinam os processos naturais.

No cenário venezuelano existe grande demanda e carência por mapas geomorfológicos. Isso se deve às diversas variáveis envolvidas no seu processo de elaboração: falta de cartas topográficas em escala compatível e com ampla abrangência de todo território nacional, a grande extensão de áreas a serem mapeadas, a dificuldade de acesso em muitas regiões, o elevado custo dos levantamentos, entre diversos outros fatores.

Porém, os atuais avanços e desenvolvimento no campo da informática, associada ao avanço das geotecnologias, potencializam o emprego de técnicas digitais na análise do relevo, apoiadas na representação da superfície terrestre na forma de Modelos Digitais Numéricos (MDN), Modelos Digitais do Terreno (MDT) ou Modelos Digitais de Elevação (MDE), que permitem extrair variáveis que representam a morfologia do relevo e podem contribuir com o avanço da cartografia geomorfológica. Esse campo do conhecimento vem sendo designado de geomorfometría.

Desta forma, o presente estudo foi realizado na bacia hidrográfica do rio Neverí, localizada na região noriental de Venezuela nos estados Anzoátegui e Sucre, cuja área é de 137.670,33 ha (Figura 1), por meio de técnicas de geoprocessamento associadas à análise digital do relevo onde determinou-se a representação paramétrica das formas do relevo, com emprego de atributos topográficos obtidos de um Modelo Digital do Elevação, elaborando-se uma compartimentação geomorfométrica.

A inferência de unidades apoiada no mapeamento automatizado do relevo segue a proposta de Iwahashi e Pike (2007), que emprega técnica de classificação não-supervisionada de formas do terreno por meio de árvore de decisões com base nos valores médios de três variáveis geomorfométricas (hipsometria, declividade, curvatura) derivadas de um MDE. 

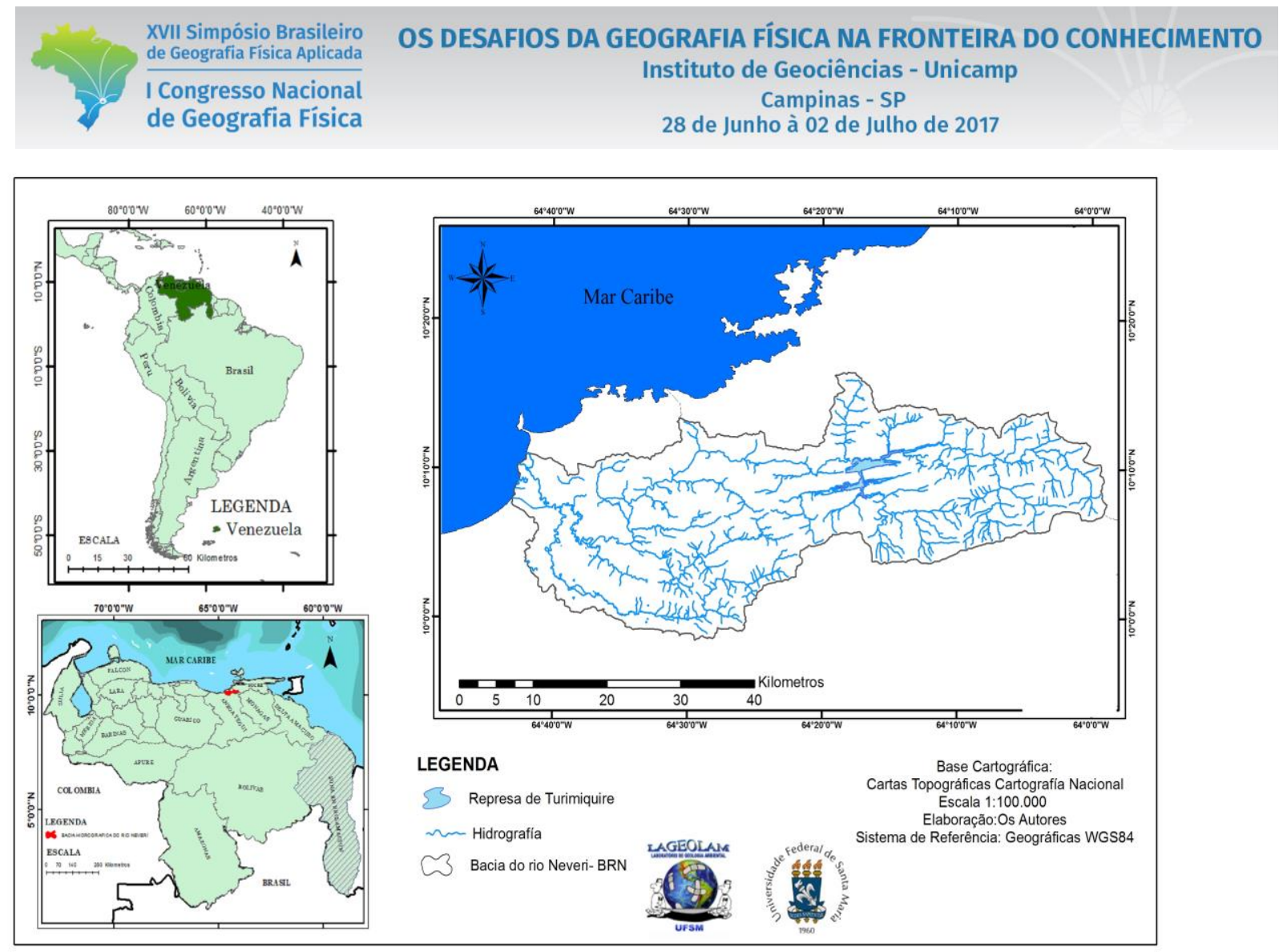

Figura 1. Localização da Bacia Hidrográfica do rio Neverí, Venezuela

\section{Materiais e Metodos}

As etapas operacionais feitas com auxílio de ferramentas de geoprocessamento em ambiente SIG foram: a) obtenção do MDE pelas curvas geradas no projeto PITSA (1998); b) geração dos atributos topográficos do relevo (hipsometria, declividade, curvatura no plano e no perfil; c) cálculo dos valores médios para discretização das variáveis e operações de álgebra de mapas para as combinações; d) organização e quantificação dos resultados obtidos pela matriz.

Na primeira etapa os dados de elevação foram obtidos do MDE a resolução espacial de 10 metros, seguidamente, desse MDE foram gerados os atributos topográficos do relevo no software ArcGIS 10.1(ESRI, 2013). Para a obtenção da declividade utilizou-se das derivadas direcionais e do modelo proposto por Horn (1981), para o plano de curvatura foi adotado o modelo proposto por Zevenbergen e Thorne (1987). A declividade corresponde a um dos mais importantes parâmetros na análise das vertentes, pois representa sua inclinação. Estas informações foram discretizadas em três classes cujo limites são $<5 \%$., $5-15 \%$ e $>15 \%$. As vertentes com altas declividades estão mais sujeitas a processos denudacionais, enquanto as de baixa são propícias aos processos agradacionais. 
A etapa seguinte consistiu em calcular os respectivos valores dos três atributos topográficos: hipsômetria (amplitude), declividade (porcentagem), curvatura (perfil e plano), logo foi realizado o cruzamento dessas informações para obter uma matriz com as unidades geomorfométricas. (Figura 3). As formas das vertentes podem ser definidas de maneira simplificada como um elemento da superfície terrestre inclinado em relação à horizontal, que apresenta um gradiente e uma orientação no espaço (VELOSO, 2002).

Para a compartimentação geomorfométrica do referido trabalho, optou-se pela classificação das curvaturas das vertentes em duas classes: quanto ao perfil em côncavas e convexas e quanto ao plano em convergentes e divergentes, conforme tabela I.

Tabela I - Estrutura das informações básicas para a determinação das unidades geomorfométricas

\begin{tabular}{|l|l|l|l|}
\hline Altitude & Declividade & Plano & Perfil \\
\hline $1<$ Média & $1<5 \%$ & 1 Convergente & 1 Convexo \\
\hline $2>$ Média & $2-5-15 \%$ & 2 Divergente & 2 Côncavo \\
\hline & $3>15 \%$ & & \\
\hline
\end{tabular}

Fonte: Os autores

Esse processo foi realizado por uma arvore de decisões, onde cada uma das três variáveis determina as possibilidades do agrupamento das unidades geomorfométricas em quinze (15) unidades geomorfométricas (Figura 2). 


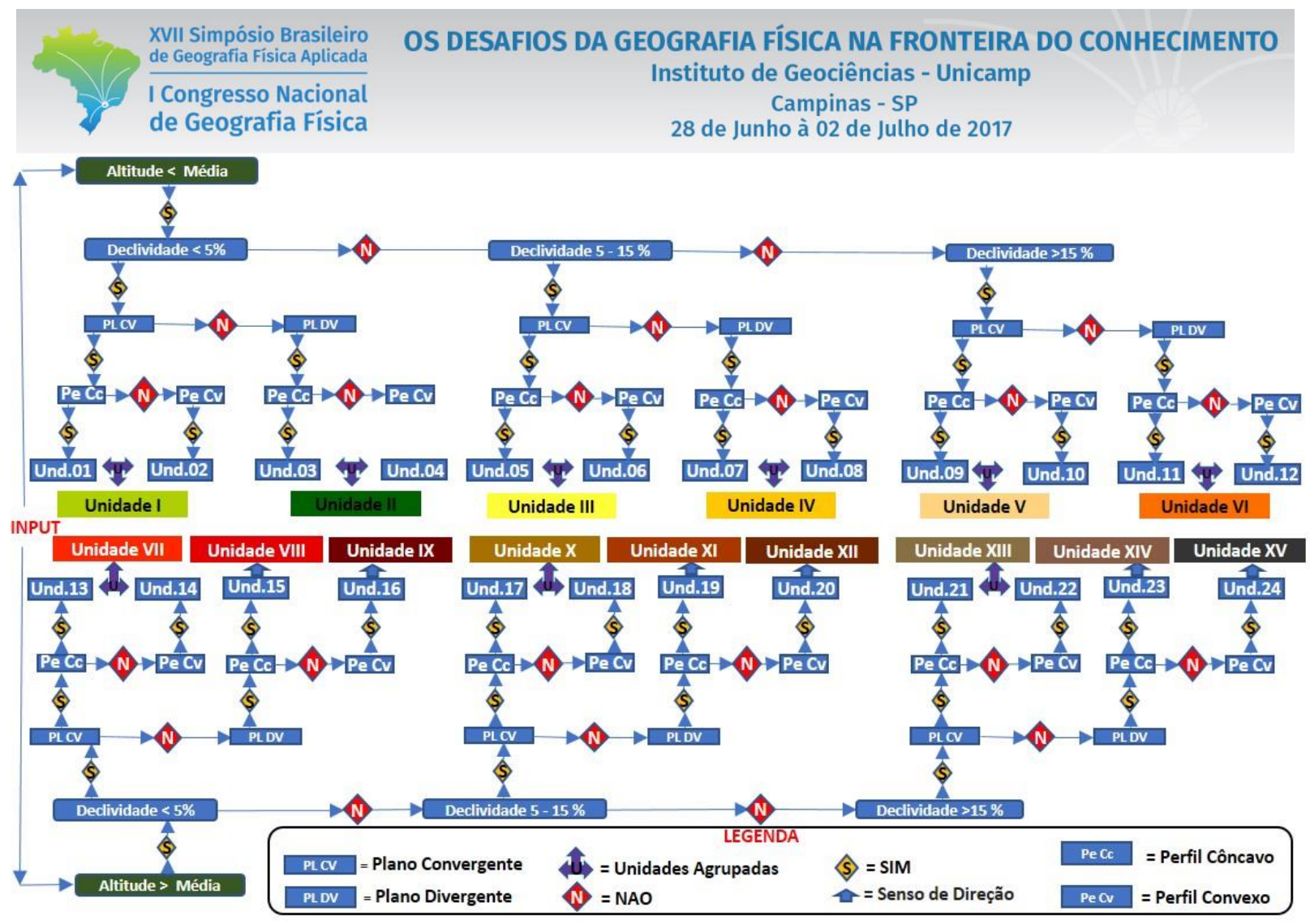

Figura 2 - Fluxograma apresentando a árvore de decisão utilizada para a definição das unidades geomorfométricas.

\section{Resultados}

Foram obtidos os atributos altitude, declividade, forma das vertentes (perfil e plano de curvatura) para definir as quinze unidades geomorfométricas. A área de estudo apresenta como menor cota altimétrica 0 (zero) metros, junto ao delta do rio Neverí onde o rio deságua no Mar Caribe, a maior cota é de 2.446 metros, resultando em uma amplitude altimétrica de $2.446 \mathrm{~m}$. A tabela II apresenta as áreas e porcentagem da área na bacia hidrografica do río Neverí e a figura 2 apresenta as unidades geomorfometricas na bacia hidrográfica. 


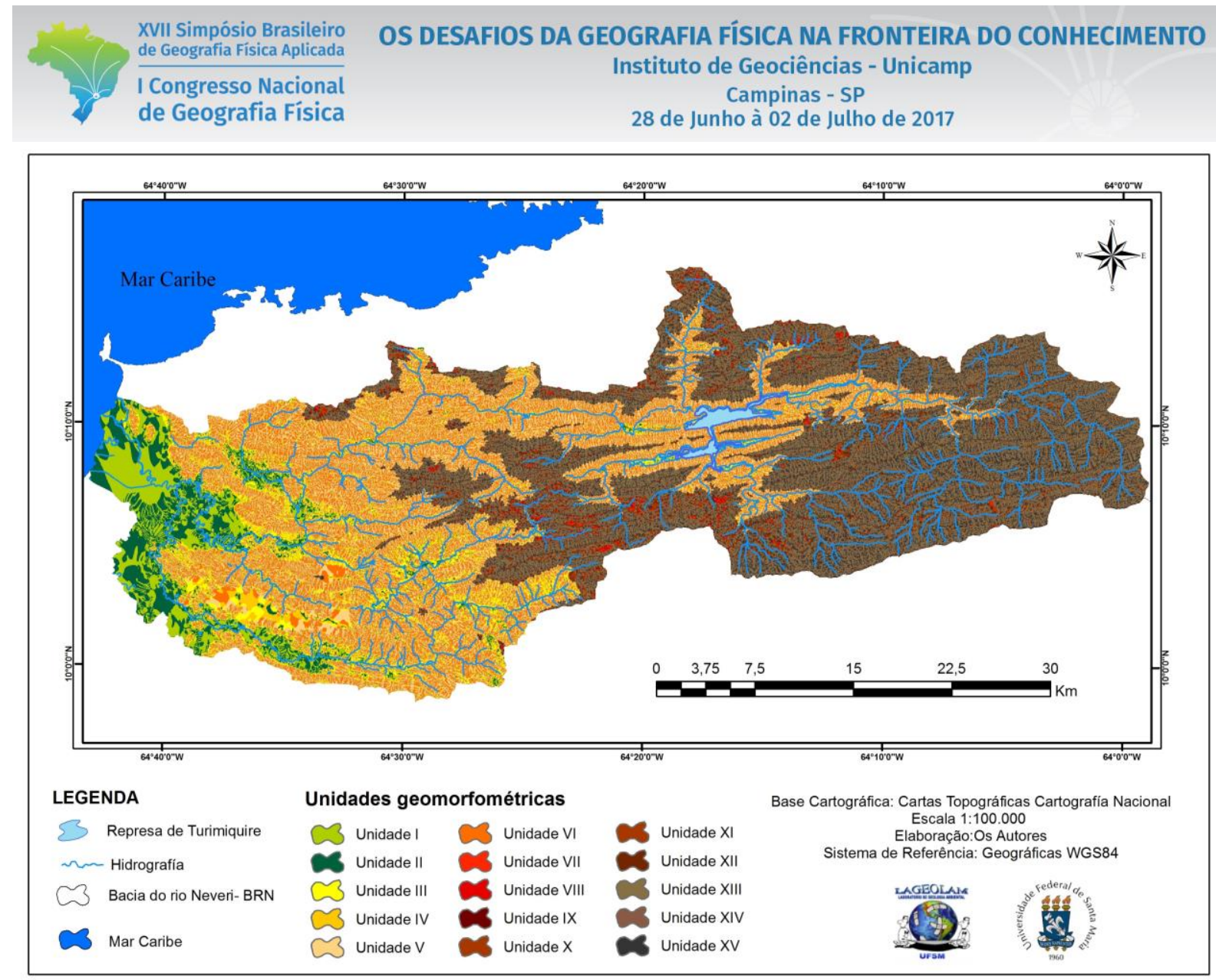

Figura 2- Mapa das unidades geomorfométricas da bacia hidrográfica do rio Neverí

Tabela II - Áreas e respectivas porcentagens das unidades geomorfométricas da bacia hidrográfica do rio Neverí

\begin{tabular}{l|l|l}
\hline \multicolumn{1}{c|}{ Unidade } & \multicolumn{1}{c}{ Área (Ha) } & \multicolumn{1}{c}{ Porcentagem (\%) } \\
\hline Unidade I & 8.294 & 6,02 \\
\hline Unidade II & $6.828,96$ & 4,96 \\
\hline Unidade III & $5.844,69$ & 4,25 \\
\hline Unidade IV & $6.073,46$ & 4,41 \\
\hline Unidade V & $24.153,79$ & 17,54 \\
\hline Unidade VI & $25.859,32$ & 18,78 \\
\hline Unidade VII & 672,08 & 0,49 \\
\hline Unidade VIII & 265,50 & 0,19 \\
\hline Unidade IX & 497,69 & 0,36 \\
\hline Unidade X & $2.572,14$ & 1,87 \\
\hline Unidade XI & $1.176,75$ & 0,85 \\
\hline Unidade XII & $1.695,46$ & 1,23 \\
\hline Unidade XIII & $26.109,37$ & 18,97 \\
\hline
\end{tabular}




\begin{tabular}{l|l|l}
\hline Unidade XIV & $12.127,65$ & 8,81 \\
\hline Unidade XV & $15.499,47$ & 11,26 \\
\hline
\end{tabular}

Fonte: Os autores

As unidades I e II apresentan uma área de 8.294 ha e 6.828,96 ha respectivamente, representando o 6,02\% e 4,96\% da área total da bacia hidrográfica. A resposta do relevo nos atributos topograficos nestas unidades foi a seguinte: a unidade I apresenta altitudes menor que a média, declividade menor que 5\% com plano convergente. São áreas expostas a processo de acumulação de água e materiais; portanto favorecem os processos depositacionais. A unidade II é composta por relevo, menor que a média da altitude, declividade menor que $5 \%$ e os planos divergentes acrecentando a planicie aluvial e permitindo a formação do delta do rio Neveri. (Ver figura 3)

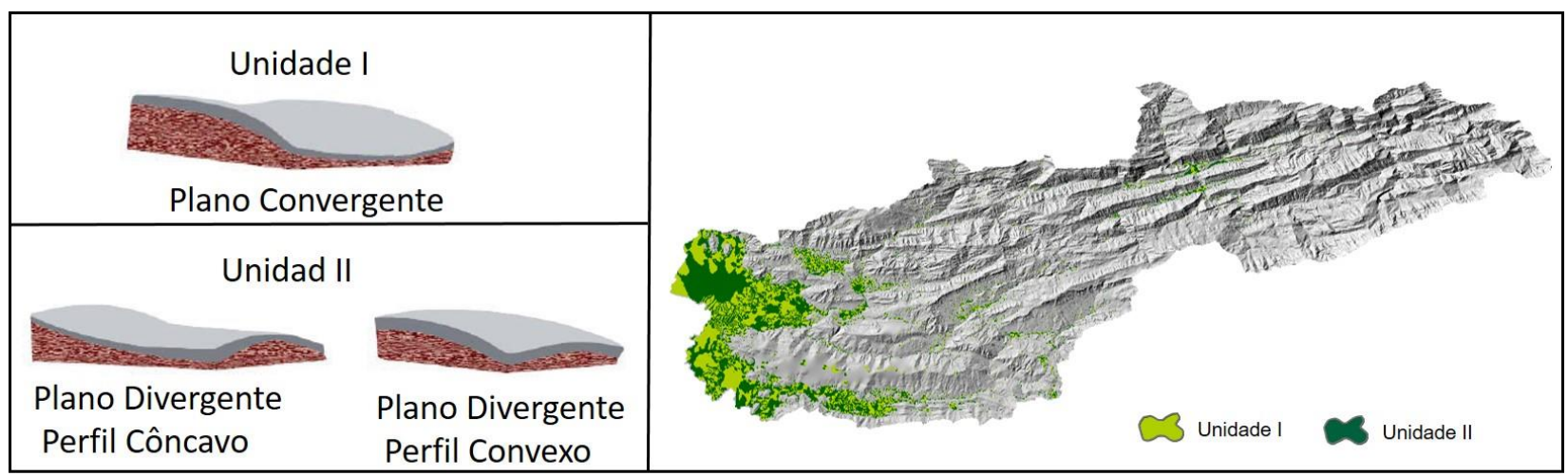

Figura 3- Formas e distribuição espacial na bacia das unidade I e unidade II

As unidades III e IV tem uma área correspondente a 5844,69 ha e 6073,46 ha com 4,25\% e 4,41\% da área total da bacia respectivamente. Na unidade III os processos de acumulação têm muita influência das declividades entre 5-15\%, portanto, apresenta-se nas áreas correspondentes a piedemonte com altitudes menor que a média e as formas das vertentes contem planos convergentes. A unidade IV também apresenta altitudes menor que a média, com declividades entorno de 5- 15\%, com planos divergentes, apresentando-se nos topos das vertentes na parte media da bacia hidrografica. Onde os processos de dispersão encontram-se condicionados a causa da declividade (Ver figura 4) 

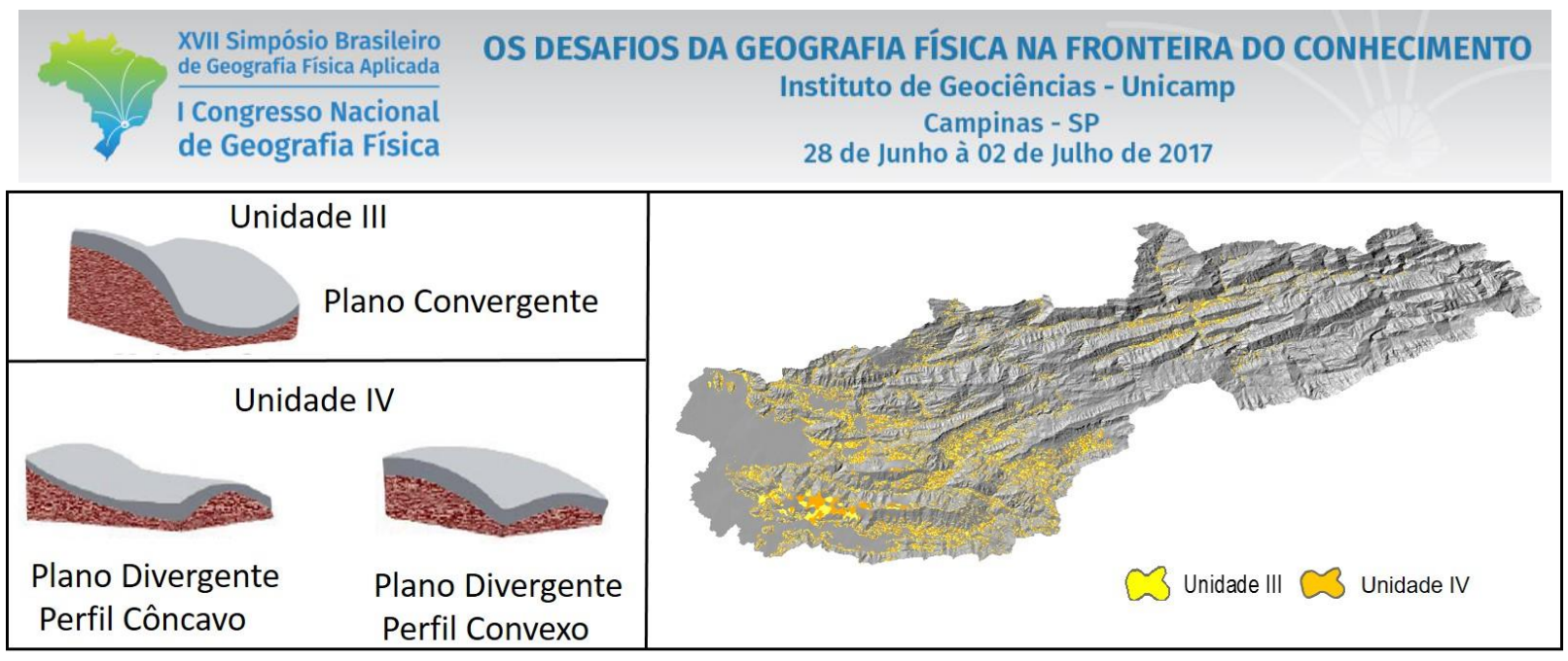

Figura 4 - Formas e distribuição espacial na bacia das unidades III e IV

A parte media e alta da bacia tem correspondência com as unidades V e VI as quais apresentam áreas de 24153,79 ha e 25859,32 ha com $17,54 \%$ e $18,78 \%$, sendo os maiores porcentagem na área total da bacia. A resposta dos atributos topograficos na unidade $\mathrm{V}$ são nas áreas com altitudes menores que a media, com declividades maior que $15 \%$ e as formas das vertentes apresentam planos convergentes; onde os processos erosivos tem uma influência forte e condicionante da declividade, portanto os processos de transporte são os mais representativos na parte media e alta da bacia. Na unidade VI os atributos topograficos apresentam um comportamento parecido a unidade $\mathrm{V}$, com uma variação na forma da vertente, onde os planos são divergentes com a disipação da energía. (Ver figura 5)

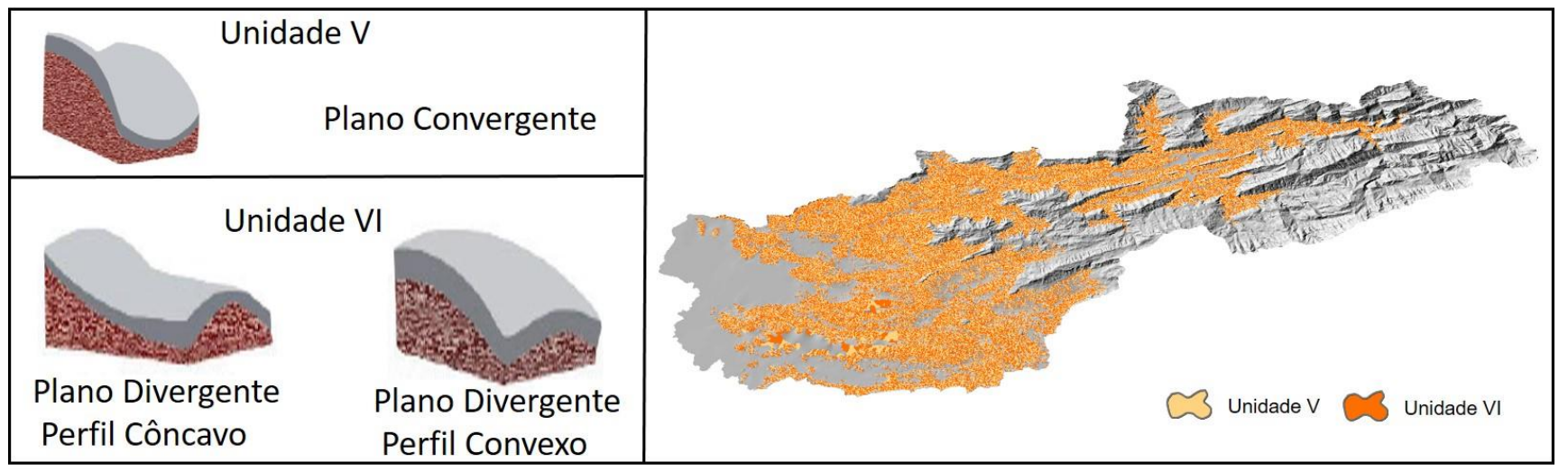

Figura 5 - Formas e distribuição espacial na bacia das unidades V e VI

Na parte média alta da bacia hidrográfica, uma porcentagem bem menor das áreas referente os atributos topográficos em altitudes maiores que a média, com a declividade menor a $5 \%$ com formas de vertentes divergentes na unidade VII, vertentes divergentes e côncavas na unidade VIII e vertentes divergentes e convexas na unidade IX correspondente as áreas do piedemonte. A unidade VII com uma área de 672,08 ha, a unidade VIII com uma área de 265, 50 ha e a unidade IX com uma área de 497, 69 ha, tem as 


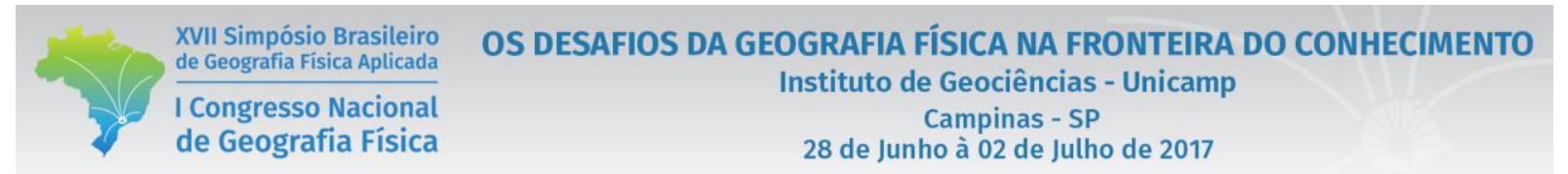

menores percentagens da área total da bacia hidrográfica, portanto, não são representativas para o nível de detalhe da compartimentação geomorfométrica. (Ver figura 6).

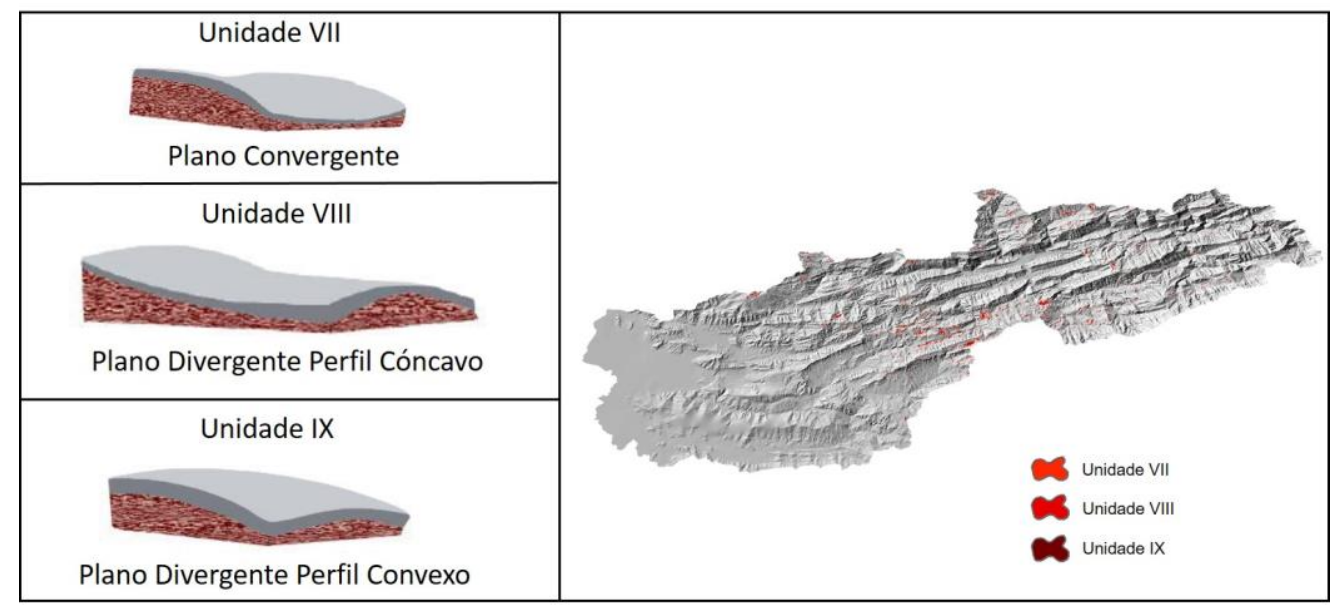

Figura 5 - Formas e distribuição espacial na bacia das unidades VII, VIII e IX

Da mesma maneira, as unidades X, XI e XII não são significativas na área total da bacia hidrográfica, cujas áreas são: a unidade X com 2.572,14 ha, unidade XI com 1176,75 ha e a unidade XII com 1695,46 ha. Essas unidades apresentam declividades entorno 5-15\% com altitudes acima da média. Os processos de acumulação e dispersão de água e material das formas de vertente convergente e divergente são condicionados pela declividade, na parte media alta do piedemonte. (Ver figura 6)

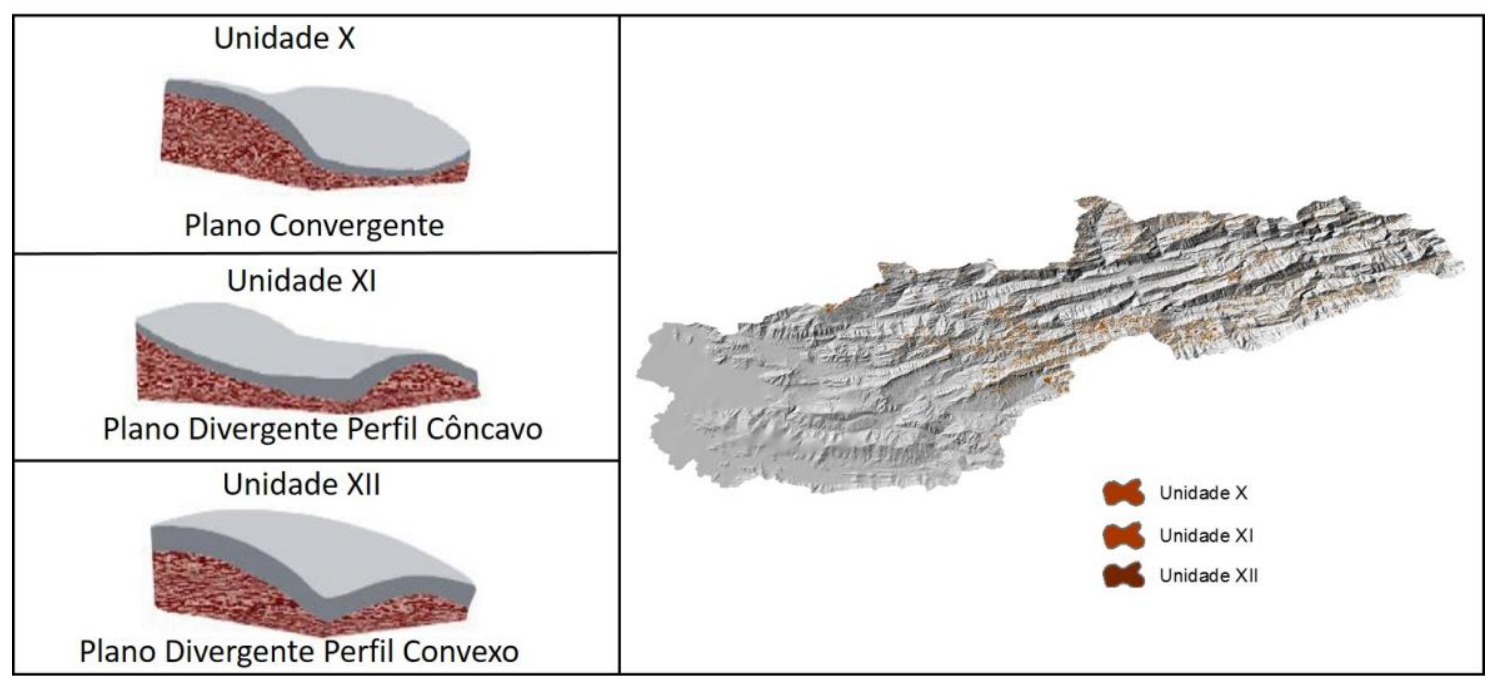

Figura 6 - Formas e distribuição espacial na bacia das unidades X, XI e XII

As unidades XIII, XIV e XV com áreas de 26.109,37 ha, 12.127,65 ha e 15.499,47 com uma somatoria de $39.04 \%$ da área total da bacia e encontram-se na parte media alta da bacia hidrográfica. Essas unidades 
respondem a altitudes maiores a media com declividades maiores a 15\%. As formas das vertentes são determinantes nos processos morfogeneticos da bacia. Os processos de acumulação encontram-se com forte influência da declividade na unidade XIII. Na unidade XIV os procesos de dispersão de material (plano divergente) presentam uma diminuição da velocidade do fluxo de água devido à concavidade da vertente. Na unidade XV os processos de dispersão dos materiais são significativos devido à forma de vertente convexa.

\section{Considerações finais}

A utilização dos atributos topograficos na compartimentação geomorfométrica parte da classificação digital das unidades com base nas caracteristicas físicas do meio relacionando diretamente á altitude, declividade e forma da vertente (curvatura plano e perfil) com diversas técnicas de geoprocessamento.

Dessa forma permite a divisão da bacia hidrografica em áreas geomorfometricamente semelhantes quanto os processos da dinâmica e modelagem da superficie (processos erosivos e de sedimentação). Neste sentido, a compartimentação geomorfometrica permitiu o agrupamento da bacia hidrografica do rio Neverí em quinze (15) unidades definidas.

As unidades mais representativas na bacia hidrográfica do rio Neverí são as unidades I e II ocupando juntas um 10,98\% da área total da bacia hidrográfica o que demostra áreas planas relacionadas aos processos deposicionais no baixo curso do rio. As unidades V e VI ocupando um 36, 33\% da área total no baixo, medio e alto curso do rio onde os processos de erosão e transporte são presentes, e finalmente as unidades XII, XIV e XV ocupando a maior porcentagem da bacia hidrográfica com um 39,03\%.

Foi constatado o potencial de aplicação do interpolador topo to raster, disponível como ferramenta no aplicativo ArcMap versão 10.1 (ESRI, 2013) obtendo um modelo digital de elevação hidrologicamente consistente, além dos seus subprodutos.

A compartimentação geomorfométrica se mostrou eficaz com grande aplicabilidade, além de ser uma alternativa viável e oferecer subsídios aos trabalhos de mapeamento preliminares. 


\section{Bibliografia}

CHRISTOFOLETTI, A. Geomorfologia. 2. ed. São Paulo: Edgard Blucher, 1980.188p

ESRI. ArcGis, Spatial Analyst, 3D Analyst. versão 10.1 Environmental Systems Research Institute, 2013

MATTOS, S. H. V. L. DE; FILHO, A. P. Complexidade e estabilidade em sistemas geomorfológicos: uma introdução ao tema. Revista Brasileira de Geomorfologia, p. 11-18, 2004.

GUADAGNIN,P.M; TRENTIN,R.. Compartimentação geomorfométrica da bacia hidrográfica do arroio Caverá - RS Geomorphometric compartmentation of hydrographic basin of the arroio cavera - RS / BRASIL. p. 183-199, 2014.

HENGL, T. Pedometric mapping: bridging the gaps between conventional and pedometric approaches. Wageningen University, Enschede, 2003. 233p. PhD thesis - Wageningen University.Disponível em:

http://spatial-analyst.net/wiki/ index.php?title=Pedometric_mapping:_PhD_thesis Acceso em: 20 jan. 2017.

HORN, B. K. P. Hill shading and the reflectance map. Proceedings of the IEEE, n. 69, v. 01, p. 14-47, 1981

IWAHASHI, J.; PIKE, R. J. Automated classifications of topography from DEMs by an unsupervised nested-means algorithm and a three-part geometric signature.Geomorphology 86(3-4): 409-440, 2007.

PENTEADO, M. M. Fundamentos de Geomorfologia. 3 ed. Rio de Janeiro: Fundação IBGE, 1985. 186p

ROSS, J. L. S. O registro cartográfico dos fato geomórficos e a questão da taxonomia do relevo. Revista do Departamento de Geografia, São Paulo, v. 6, p. 17-29, 1992. Disponible em: <http://www.revistas.usp.br/rdg/article/view/47108/50829>. Acceso en: 12 sept. 2016.

TRENTIN, R.; ROBAINA, L. E. S. As Unidades de Relevo como Base para a Compartimentação Geomorfológica da Bacia Hidrográfica do Rio Itu - Oeste do Rio Grande do Sul. In: $9^{\circ}$ SIMPÓSIO NACIONAL DE GEOMORFOLOGIA, 2012, Rio de Janeiro/RJ. Anais... Rio de Janeiro/RJ: Universidade Federal do Rio de Janeiro, 2012.

TRENTIN, R.; ROBAINA, L. E. DE S.; SILVEIRA, C. T. DA. Compartimentação geomorfométrica da bacia hidrográfica do rio itú/rs geomorphometric compartmentation of river basin Itu/RS Revista Brasileira de Geomorfologia. v. 16, n. 2, p. 219-237,2015.

VELOSO, A. A importância do estudo das vertentes. Geographia, v. 4, n. 8, p 1-5, 2002

WOOD, J. The geomorphological characterisation of digital elevation models. Leicester, UK, 1996. 185p. PhD Thesis - University of Leicester.Disponível em: http://www.soi.city.ac.uk/ jwo/phd. 


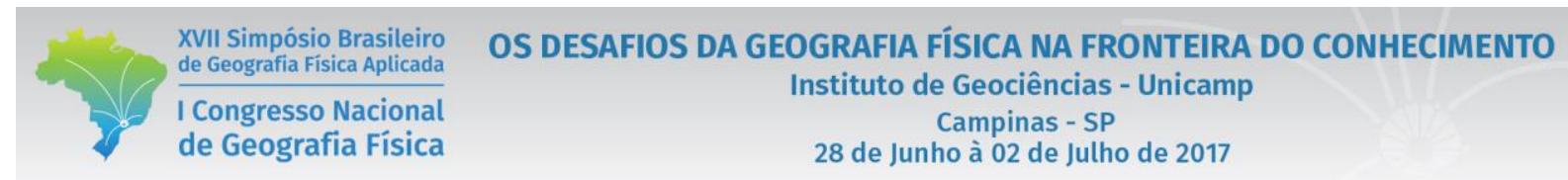

ZEVENBERGEN, L.W.; THORNE, C.R. Quantitative Analysis of Land Surface Topography.Earth Surface Processes and Landforms, v.12, p.47-56, 1987 